\title{
Unemployment in COVID-19 Pandemic Times - A Glimpse of India
}

\section{Damayanti Sen}

\author{
Department of Economics \\ The Bhawanipur Education Society College, Kolkata \\ Residential Address: CK 110 Salt Lake Kolkata, West Bengal, India, PIN CODE 700091 \\ *Corresponding author details: Assistant Professor Damayanti Sen; \\ damayantisen20@gmail.com
}

\begin{abstract}
COVID-19 has struck human lives in a two-pronged way - through one prong, it has infected people and taken the lives away, through the other prong it has pushed mankind to run into severe unemployment leading to unconditional misery. India's sufferings, like all other countries, have rose to unprecedented levels during the COVID times throttled by both the prongs. This study is an insight into the unemployment levels which India has experienced during COVID times vis-s-vis the pre-COVID times. The paper has depicted the dismal picture of sky-rocketing unemployment rates and educated unemployment rates in Covid times in overall India. A comparison with reasoning has been given to the situation in the two states of West Bengal and Tamil Nadu with diagrams and Sopher's Index. Data is not yet found for the second wave of Covid which struck in April 2021. This would have added to the dismal picture.
\end{abstract}

Keywords: unemployment rate; educated unemployment rate; Sopher's Index; COVID; India; West Bengal; Tamil Nadu

\section{INTRODUCTION}

COVID-19 has struck human lives in a two-pronged way through one prong, it has infected people and taken the lives away, through the other prong it has pushed mankind to run into severe unemployment leading to unconditional misery. India's sufferings, like all other countries, have rose to unprecedented levels during the COVID times throttled by both the prongs. This study is an insight into the unemployment levels which India has experienced during COVID times vis-s-vis the pre-COVID times. India consists of 29 states and different states have had different experiences. West Bengal and Tamil Nadu are two major contributors to India's GDP. Besides, almost every year, a major chunk of the graduated students from West Bengal go to Tamil Nadu for jobs. So, along with an overall picture of India, the study has tried to provide a glimpse into the inside story via the experiences of these two states. The paper is arranged in the following way - Section 2 gives the data and the methodology, Section 3 provides the results, Section 4 gives the conclusion and Section 5 gives the References.

\section{DATA AND METHODOLOGY}

- Source of Data: The paper has used secondary data, taken from the Statistical Profiles published by Centre for Monitoring Indian Economy (CMIE).

- Study Period: As pre-COVID times, two periods have been chosen - May to August 2019 and September to December 2019.The next four periods show the COVID times - January to April 2020, May to August 2020, September to December 2020 and January to April 2021.

\section{- Definitions:}

a) Unemployment Rate (UER): These are people who are unemployed and are willing to work and are actively looking for a job, expressed as a percentage of the labour force. b) Educated Unemployment Rate: These are people having educational degree of graduation and above, who are willing to work and actively looking for work, but are unemployed, expressed as a percentage of the graduate labour force.

\footnotetext{
- Methodology: Data from the above periods of overall unemployment rates as well as educated unemployment rates have been presented using descriptive tools. The comparison of West Bengal vis-à-vis Tamil Nadu has been done by constructing the Sopher's Index (1974) of regional disparity. If $\mathrm{X} 1$ and $\mathrm{X} 2$ represent the respective percentage of the variables of groups 1 and 2, then the Sopher's index of inequality $D$ is: $\mathrm{D}=\log (\mathrm{X} 2 / \mathrm{X} 1)+\log (\mathrm{Q}-\mathrm{X} 1) /(\mathrm{Q}-\mathrm{X} 2)$
}

The objective of taking logarithm is to reduce the levelling off effects (region with high level of attainment may have low level of disparity and vice versa). Sopher's Index has a number of useful properties like (1) It ranges from minus infinity to plus infinity and each of these extremes are possible if one group totally lacks the property or when all members of one group have the property; (2) Obviously if there is no inequality then $D=0$. Therefore, any deviation from zero is inequality. (3) A positive value implies X2 has higher values than $\mathrm{X} 1$, while a negative value indicates the reverse. Also, higher the absolute value of $\mathrm{D}$, higher the inequality; (4) The sign is reversed when the disparity is measured in the reverse direction, that is, rural-urban is made urban-rural gap; (5) the sign also gets reversed when the absence of the property is measured, (6) The index is additive, that is, the sum of disparity between groups A and $\mathrm{B}$ and the disparity between $\mathrm{B}$ and $\mathrm{C}$, is equal to the disparity between groups A and C. We consider X1 as West Bengal and X2 as Tamil Nadu. 


\section{RESULTS}

\section{(1) Overall Picture of India}

Figure 1 represents the overall unemployment rates for India in the Covid times vis-à-vis pre-COVID times. It is clear that COVID has hard hit employment in all sectors as unemployment rate rises sharply from January 2020 to August 2020

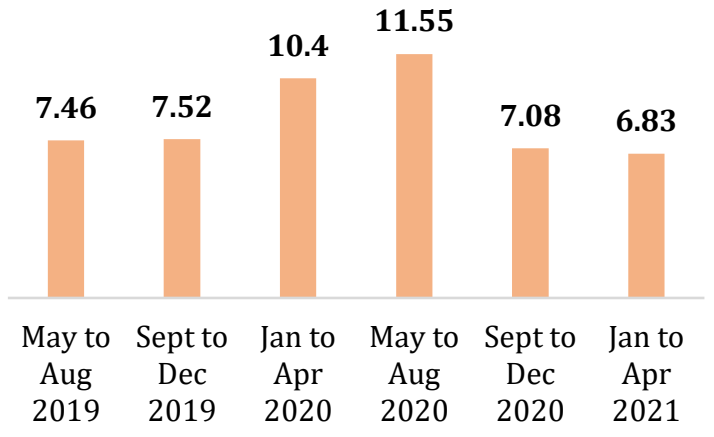

FIGURE 1: India - Overall Unemployment Rates

Figure 2 depicts another dismal picture. The educated unemployment rate has sky-rocketed from May 2020. This is an indication that most of the students who graduated in May 2020 did not employment.

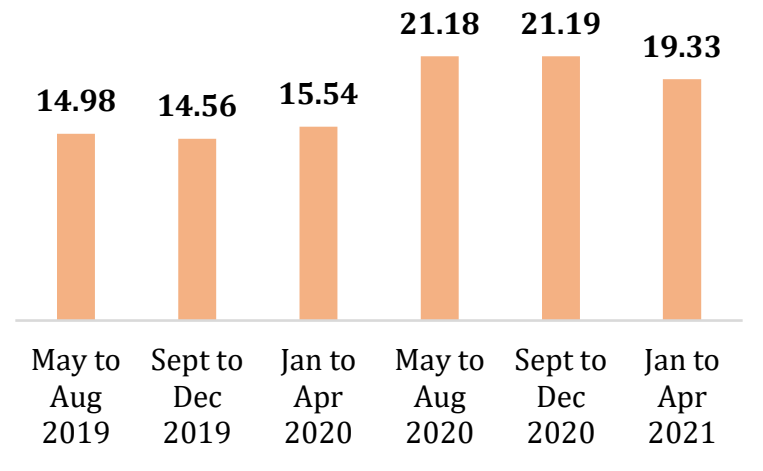

FIGURE 2: India - Educated Unemployment Rates

(2) Comparison of West Bengal vis-à-vis Tamil Nadu West Bengal and Tamil Nadu are both major contributors of GDP in India. Besides most of the graduates from West Bangal choose Tamil Nadu as their workplace.

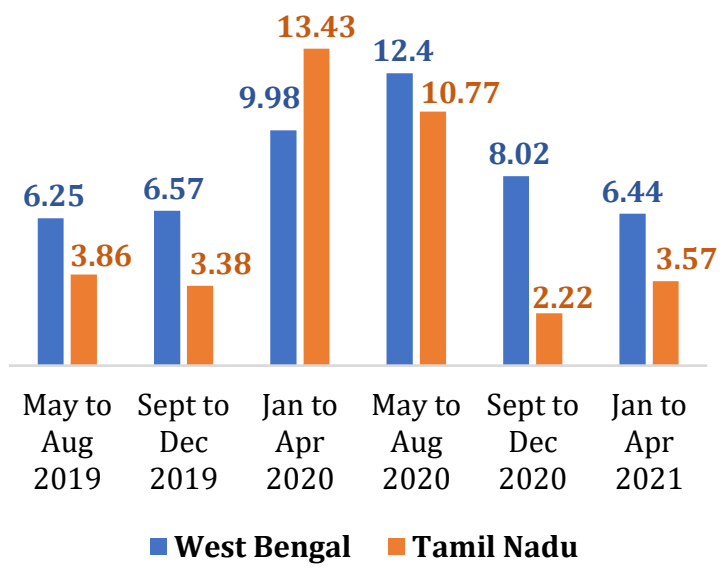

FIGURE 3: Overall Unemployment Rates

Figure 3 shows the overall experiences of West Bengal and Tamil Nadu. In pre-COVID times, Tamil Nadu has fared much better, however from January to April 2020, Tamil Nadu's unemployment rate has far surpassed that of West Bengal, the most probable reason of the rapid spread of the infection in the South than the North. However, Tamil Nadu has managed to bring down its unemployment level largely.

The disparity in overall unemployment is well captured in Figure 4 where the Sopher's Index has been plotted. A negative value indicates West Bengal has higher Unemployment than Tamil Nadu, while a positive value is just the reverse.

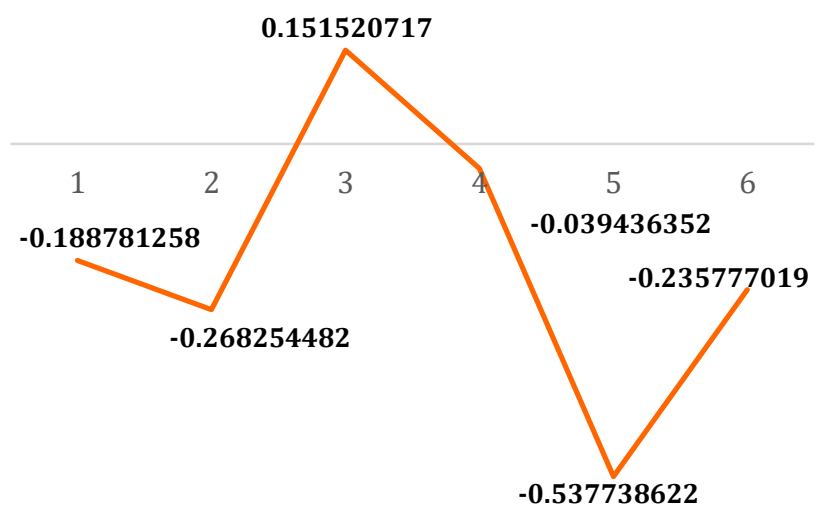

FIGURE 4: Sopher's Index

Figure 5 shows the educated unemployment rates in West Bengal and Tamil Nadu. Throughout the time span. it is less in Tamil Nadu than in West Bengal. This may be justified on the grounds that there had been inter-state lockdown. So, most of the graduates leaving for Tamil Nadu for jobs had to stay back in West Bengal thereby towering West Bengal's Educated Unemployment rates.

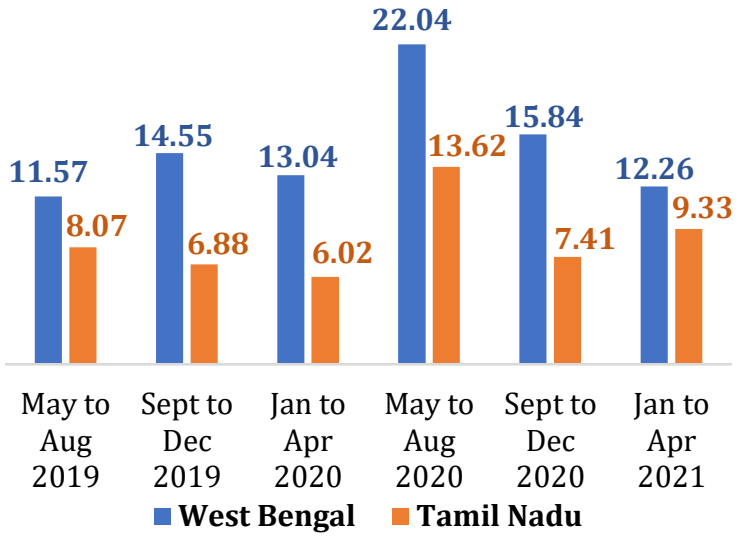

FIGURE 5: Educated Unemployment Rates

Figure 6 shows that Sopher's Index takes negative values throughout, the most extreme values being taken in the months of January to April 2020 and September to December 2020.

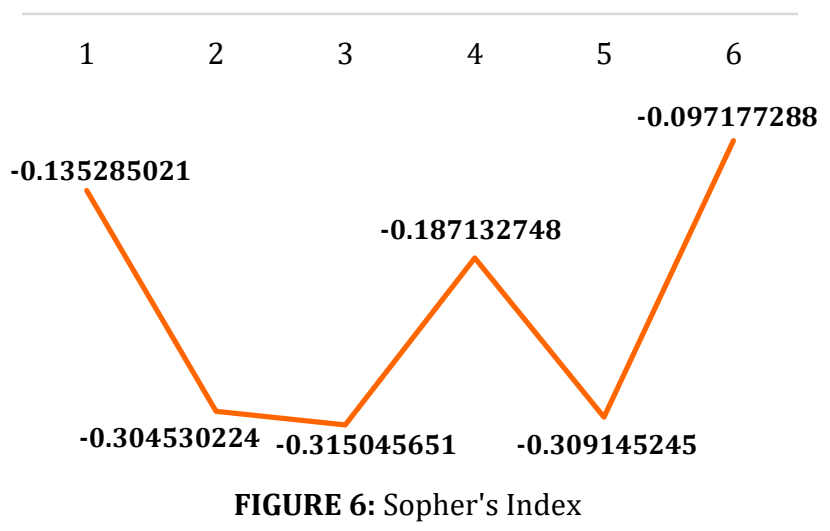




\section{CONCLUSION}

The paper has depicted the dismal picture of sky-rocketing unemployment rates and educated unemployment rates in Covid times in overall India. A comparison with reasoning has been given to the situation in the two states of West Bengal and Tamil Nadu with diagrams and Sopher's Index. Data is not yet found for the second wave of Covid which struck in April 2021. This would have added to the dismal picture.

\section{REFERENCES}

[1] CMIE. (2019). Unemployment in India a Statistical Profile May -August 2019. Kolkata: Centre for Monitoring Indian Economy.

[2] CMIE. (2019). Unemployment in India a Statistical Profile September - December 2019. Kolkata: Centre for Monitoring Indian Economy.
[3] CMIE. (2020). Unemployment in India a Statistical Profile January to April 2020. Kolkata: Centre for Monitoring Indian Economy.

[4] CMIE. (2020). Unemployment in India a Statistical Profile May -August 2020. Kolkata: Centre for Monitoring Indian Economy.

[5] CMIE. (2020). Unemployment in India a Statistical Profile September to December 2020. Kolkata: Centre for Monitoring Indian Economy.

[6] CMIE. (2021). Unemployment in India a Statistical Profile January to April 2021. Kolkata: Centre for Monitoring Indian Economy.

[7] Hussain, Z., \& Sarkar, S. (2011). Gender Disparities in Educational Trajectories in India: Do Females Become More Robust at Higher Levels? Social Indicators Research, 101(1), 37-56. 